\title{
Analytical Efficiency Evaluation of Modular Multilevel Converter for HVDC System
}

\author{
Ehtasham Mustafa \\ Department of Electrical Engineering, University of \\ Engineering \& Technology, Peshawar, Pakistan.
}

\begin{abstract}
Modular Multilevel Converter (MMC) is becoming a strong alternative converter for Voltage Source Converter (VSC) due to its control and flexibility. Considering the importance of the losses estimation in the design process, an analytical method is proposed to calculate the power losses in each switching device of a sub module of Modular Multilevel Converter (MMC). Average and root mean square of the sub module current is used to calculate the conversion losses (conduction and switching). The method is applied on a full bridge sub module topology. Then considering a case, with certain parameters a MATLAB program is developed to analyze the results for the proposed method.
\end{abstract}

\section{General Terms}

High Voltage Direct Current, Converters

\section{Keywords}

Modular Multilevel Converter (MMC), Conversion Losses, Full Bridge Sub Module, Efficiency, IGBTs, Free Wheeling Diodes

\section{INTRODUCTION}

In recent times, MMC has been widely accepted as the most concerned converter topology in the HVDC transmission system. It has features of low switching frequency, low converter losses and flexible control. MMC has a very

\author{
Muhammad Naeem Arbab \\ Department of Electrical Engineering, University of \\ Engineering \& Technology, Peshawar, Pakistan
}

\begin{abstract}
complex topology structure, having large number of sub modules, resulting in the difficulty of stating the formulae for the losses. During the design stage of the MMC based HVDC system, the loss estimation stage is an important step, as it helps the designer to optimize the overall system performance, select the heat sinking equipment and cooling systems for the system. Therefore, it is important to make a research on the loss calculation method of MMC and state formulae for the losses.

In this paper, the structure of MMC based HVDC system is discussed. Then, an analytical method based on average current and root mean square (RMS) of the current passing through the sub module is presented to calculate the conversion losses in the switching devices of MMC. The method is applied considering the full bridge sub module topology. Then, considering a case with certain parameters, a MATLAB program is developed and the losses and efficiency curves for each switching device and sub module are obtained respectively. Also, those factors which affect the losses and efficiency of the sub module are discussed.
\end{abstract}

\section{MMC BASED HVDC SYSTEM STRUCTURE}

Figure 1 shows the structure of MMC based HVDC system. The system consists of the following components:

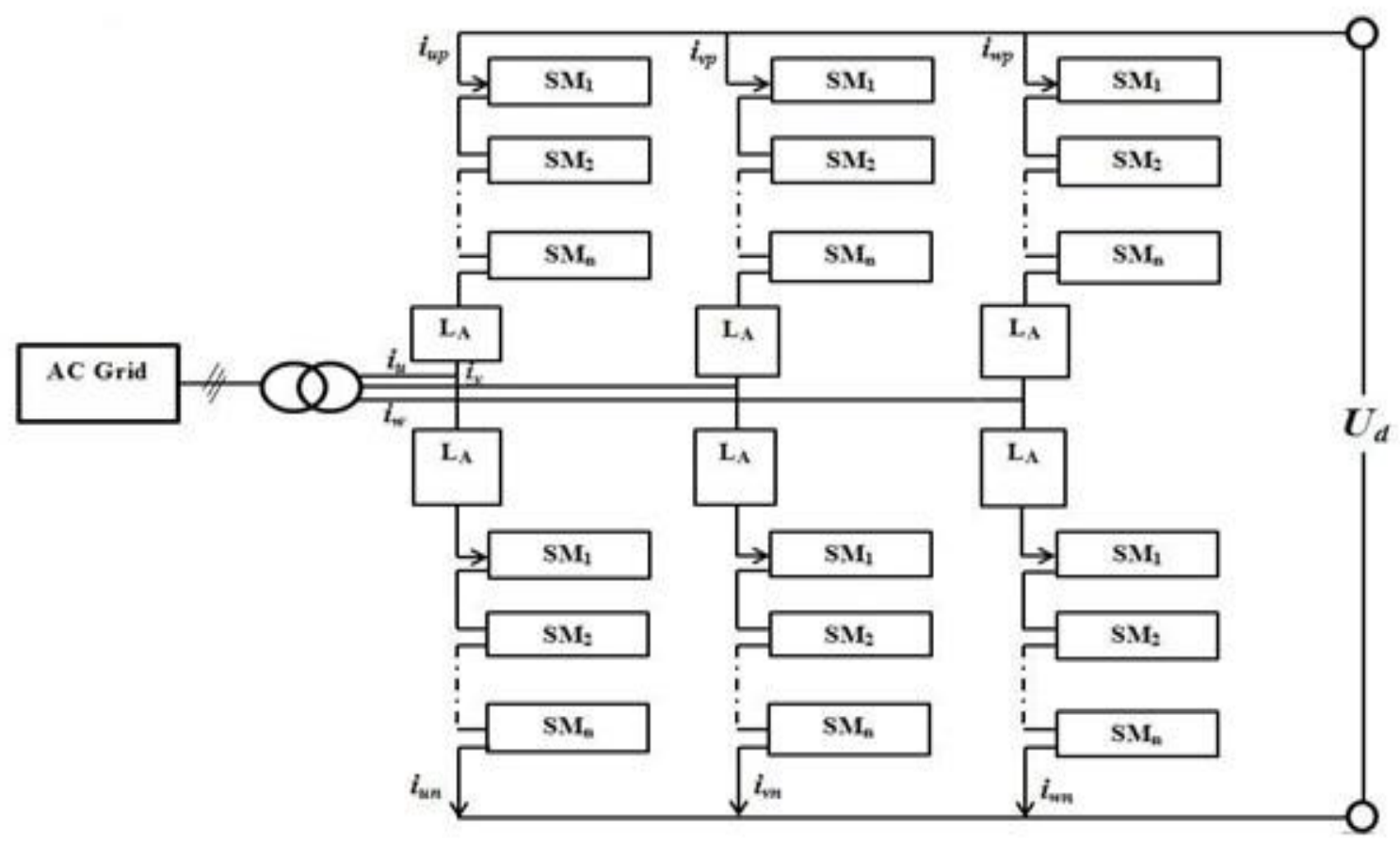

Figure 1: MMC based HVDC System 


\section{Coupling Transformer}

The coupling transformer changes the voltage level at the ac side to the level which is suitable for the MMC

\section{AC Grid}

The AC grid is the part whose state is converted to DC.

\section{Arm Inductance}

Arm inductance serves multiple purposes; to limit the current during fault, as filter for ac current and to limit the circulating current among the legs which is of high harmonics.

\section{Sub Module}

A sub module or cell is a basic building block of the MMC. It is a two terminal device consisting of combination of IGBTs, diodes and capacitors used to generate the required voltage level.

\section{Arm}

A series connected sub modules and arm inductance forms an arm.

\section{Phase Leg}

Combination of two phase arms is known as phase leg.

\subsection{Circuit Analysis}

Figure 1 shows the structure of MMC based HVDC system. Assuming the losses of each phase is steady, for a three phase balance working condition. Then, only phase $\mathrm{U}$ is selected for the loss analysis. The current through the arm of phase $\mathrm{U}$ is:

$I_{u u}=\frac{I_{u}}{2} \sin (\omega t+\varphi)+I_{u d}+I_{u z} \sin (2 \omega t+\theta)$

$\mathrm{I}_{\mathrm{ul}}=-\frac{\mathrm{I}_{\mathrm{u}}}{2} \sin (\omega \mathrm{t}+\varphi)+\mathrm{I}_{\mathrm{ud}}+\mathrm{I}_{\mathrm{uz}} \sin (2 \omega \mathrm{t}+\theta)$

The terms $\mathrm{I}_{\mathrm{uu}}$ and $\mathrm{I}_{\mathrm{ul}}$ represent the current through the upper and lower arms respectively. In the above equations, $I_{u}$ is the maximum value of the phase current. $I_{u d}$ is the DC component in arm current, which is one third of the DC line current. The last element, $\mathrm{I}_{\mathrm{uz}}$ is the circulating current having double line frequency. The fluctuation in the sub module's capacitor voltage results in the fluctuation of the arm voltage. This fluctuation produces the circulating current.

\section{CONVERSION LOSSES}

The conversion losses of MMC can be divided into two parts: $[1,2]$

\subsection{Conduction Losses}

The on state voltages drop in the device produces the conduction losses. These losses are computed by averaging the conduction losses in each switching cycle [2] as shown in equation (3).

$P_{\text {con }}=\frac{1}{T} \int_{0}^{t} V_{f}(\omega t) i(\omega t) d \omega t$

Where, $\mathrm{P}_{\text {con }}$ shows the conduction losses of the device $V_{f}(\omega t)$ shows the forward voltage drop of the device and $\mathrm{i}(\omega \mathrm{t})$ represents the current flowing through the device during the conduction period. $\mathrm{T}$ is the switching period. The forward voltage drop is calculated by using the following equation:

$\mathrm{V}_{\mathrm{f}}=\mathrm{V}_{\mathrm{f} 0}+\mathrm{r}_{\mathrm{f}} \mathrm{i}(\omega \mathrm{t})$

Where $V_{f 0}$ and $r_{f}$ show the forward voltage drop of the device at no load and the device forward resistance respectively. The device's data sheet provided by the manufacturer is used to calculate $V_{\mathrm{fo}}$ and $\mathrm{r}_{\mathrm{f}}$. Substituting equation (4) into equation (3), results in equation (5).
$\mathrm{P}_{\text {con }}=\mathrm{V}_{\mathrm{f}} \mathrm{I}_{\mathrm{av}}+\mathrm{I}_{\mathrm{rms}}^{2} \mathrm{r}_{\mathrm{f}}$

$\mathrm{I}_{\mathrm{av}}$ is the average current flowing through the device while $I_{\text {rms }}$ is the root mean square value of the current flowing through the device. These values of the current are calculated by using equation (6) and (7) respectively.

$\mathrm{I}_{\mathrm{av}}=\frac{1}{\mathrm{~T}} \int_{0}^{\mathrm{t}} \mathrm{i}(\omega \mathrm{t}) \mathrm{d} \omega \mathrm{t}$

$\mathrm{I}_{\text {rms }}^{2}=\frac{1}{\mathrm{~T}} \int_{0}^{\mathrm{t}} \mathrm{i}^{2}(\omega \mathrm{t}) \mathrm{d} \omega \mathrm{t}$

\subsection{Switching Losses}

The combination of turning on losses and turning off losses results in the switching losses of the device. These losses depend on the device characteristics, switching frequency and the current, which is flowing through the device [3]. Following relationship is used for the calculation of the switching losses of the device:

$\mathrm{P}_{\mathrm{sw}}=\frac{\mathrm{f}_{\mathrm{s}}}{2 \pi} \int_{0}^{\mathrm{t}} \mathrm{ki}(\omega \mathrm{t}) \mathrm{d} \omega \mathrm{t}$

Where $\mathrm{P}_{\mathrm{sw}}$ are the device switching losses, $\mathrm{k}$ is constant and is obtained from the switching energy graph of the device which is given in the data sheet. $\mathrm{f}_{\mathrm{s}}$ is the switching frequency of the device.

\section{CONVERSION LOSSES EVALUATIO OF FULL BRIDGE SUB MODULE}

A full bridge sub module is shown in the Figure 2 this type of sub module topology consists of a dc capacitor and four power electronic switching devices. Each switching device consists of IGBT and free-wheeling diode. The terminal voltage of the sub module depends on the states of the four switches [4]. The terminal voltage of the sub module is either equal to capacitor voltage or zero or negative of the capacitor voltage. Table I shows the switching pattern and terminal voltage of the full bridge sub module. In this sub module topology two IGBTs in one pair cannot have on signal at the same time as it will result in short circuit condition.

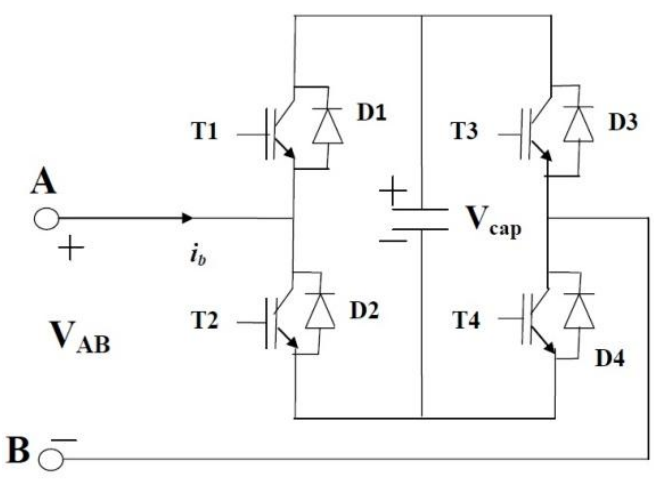

Figure 2: Full Bridge Sub Module

For the losses calculation, the current and voltage waveforms of the switching devices must be known. The current and voltage waveform of each switching device depends on the pulse waveform of the switching device. Also, if the phase current is assumed to be constant then the switching function can be replaced by the device duty cycle within the switching cycle. Considering Sinusoidal Pulse Width Modulation (SPWM), as the switching technique for the switching devices, the losses in each switching device is calculated. 
Table 1. Switching States of IGBTs

\begin{tabular}{|c|c|c|c|c|}
\hline \multicolumn{4}{|c|}{ IGBTs States } & \multirow{2}{*}{$\mathbf{V}_{\mathrm{AB}}$} \\
\hline T1 & T2 & T3 & T4 & \\
\hline 1 & 0 & 0 & 1 & $\mathrm{~V}_{\text {cap }}$ \\
\hline 1 & 0 & 1 & 0 & 0 \\
\hline 0 & 1 & 0 & 1 & 0 \\
\hline 0 & 1 & 1 & 0 & $-\mathrm{V}_{\text {cap }}$ \\
\hline
\end{tabular}

Using $\mathrm{i}_{\mathrm{b}}$; bridge current, to represent the current flowing through the full bridge sub module in the upper arm. This current is equal to the phase current flowing through the upper $\operatorname{arm} \mathrm{I}_{\mathrm{uu}}$. Then, the duty cycles of the switching devices is:

$D_{T 1}=D_{D 1}=D_{T 4}=D_{D 4}=M \sin \omega t$

$D_{T 1}^{\prime}=D_{D 1}^{\prime}=D_{T 3}=D_{D 3}=1-M \sin \omega t$

$D_{T 2}=D_{D 2}=D_{T 4}^{\prime}=D_{D 4}^{\prime}=1+M \sin \omega t$

$D_{T 2}^{\prime}=D_{D 2}^{\prime}=D_{T 3}^{\prime}=D_{D 3}^{\prime}=-M \sin \omega t$

The average current and RMS currents for IGBTs, T1 to T4 for each switching period are calculated below by using equations (6) and (7) respectively. For the switching period of $\mathrm{T} 1$ and $\mathrm{T} 4$,

$\mathrm{I}_{\mathrm{T} 1}=\frac{1}{2 \pi} \int_{0}^{\pi} \mathrm{I}_{\mathrm{uu}} \mathrm{D}_{\mathrm{T} 1} \mathrm{~d} \omega \mathrm{t}=\frac{1}{2 \pi}\left[\frac{\pi}{4} \mathrm{MI}_{\mathrm{u}} \cos \varphi+2 \mathrm{MI}_{\mathrm{ud}}-\right.$ 23MIuzsin $\theta$

$\mathrm{I}_{\mathrm{T} 4}=\mathrm{I}_{\mathrm{T} 1}=\frac{1}{2 \pi}\left[\frac{\pi}{4} \mathrm{MI}_{\mathrm{u}} \cos \varphi+2 \mathrm{MI}_{\mathrm{ud}}-\frac{2}{3} \mathrm{MI}_{\mathrm{uz}} \sin \theta\right]$

$\mathrm{I}_{\text {rmsT } 1}^{2}=\frac{1}{2 \pi} \int_{0}^{\pi} \mathrm{I}_{\mathrm{uu}}^{2} \mathrm{D}_{\mathrm{T} 1} \mathrm{~d} \omega \mathrm{t}=\frac{1}{2 \pi}\left[\frac{\mathrm{I}_{u}^{2}}{4} \mathrm{M}\left[1+\frac{\cos 2 \varphi}{3}\right]+2 \mathrm{I}_{\mathrm{ud}}^{2} \mathrm{M}+\right.$ Iuz2 $\mathrm{M} 1+\cos 2 \theta 15$

$\mathrm{I}_{\text {rmsT 4 }}^{2}=\mathrm{I}_{\text {rms } 1}^{2}$

For the period when $\mathrm{T} 1$ and $\mathrm{T} 3$ are conducting,

$\mathrm{I}_{\mathrm{T} 1}=\frac{1}{2 \pi} \int_{0}^{\pi} \mathrm{I}_{\mathrm{uu}} \mathrm{D}_{\mathrm{T} 1}^{\prime} \mathrm{d} \omega \mathrm{t}=\frac{1}{2 \pi}\left[\frac{\mathrm{I}_{\mathrm{u}}}{2} \cos \varphi\left(1-\frac{\pi \mathrm{M}}{4}\right)+\right.$ Iud $\pi-2 \mathrm{M}+23 \mathrm{MIuzsin} \theta$

$\mathrm{I}_{\mathrm{T} 3}=-\mathrm{I}_{\mathrm{T} 1}=-\frac{1}{2 \pi}\left[\frac{\mathrm{I}_{\mathrm{u}}}{2} \cos \varphi\left(1-\frac{\pi \mathrm{M}}{4}\right)+\mathrm{I}_{\mathrm{ud}}(\pi-2 \mathrm{M})+\right.$

23MIuzsin $\theta$

$\mathrm{I}_{\mathrm{rmsT} 1}^{2}=\frac{1}{2 \pi} \int_{0}^{\pi} \mathrm{I}_{\mathrm{uu}}^{2} \mathrm{D}_{\mathrm{T} 1}^{\prime} \mathrm{d} \omega \mathrm{t}=\frac{1}{2 \pi}\left[\frac{\mathrm{I}_{\mathrm{u}}^{2}}{4}\left(\frac{\pi}{2}-\mathrm{M}\left[1+\frac{\cos 2 \varphi}{3}\right]\right)+\right.$ $\operatorname{Iud} 2 \pi-2 \mathrm{M}+\operatorname{Iuz} 2 \pi 2-\mathrm{M} 1+\cos 2 \theta 15$

$\mathrm{I}_{\mathrm{rmsT} 3}^{2}=\mathrm{I}_{\text {rmsT } 1}^{2}$

For the period $\mathrm{T} 2$ and $\mathrm{T} 4$ are in on-state,

$\mathrm{I}_{\mathrm{T} 4}=\frac{1}{2 \pi} \int_{0}^{\pi} \mathrm{I}_{\mathrm{uu}} \mathrm{D}_{\mathrm{T} 4}^{\prime} \mathrm{d} \omega \mathrm{t}=\frac{1}{2 \pi}\left[\frac{\mathrm{I}_{\mathrm{u}}}{2} \cos \varphi\left(1+\frac{\pi \mathrm{M}}{4}\right)+\right.$ Iud $\pi+2 \mathrm{M}-23$ MIuzsin $\theta$

$\mathrm{I}_{\mathrm{T} 2}=-\mathrm{I}_{\mathrm{T} 4}=-\frac{1}{2 \pi}\left[\frac{\mathrm{I}_{\mathrm{u}}}{2} \cos \varphi\left(1+\frac{\pi \mathrm{M}}{4}\right)+\mathrm{I}_{\mathrm{ud}}(\pi+2 \mathrm{M})-\right.$ 23MIuzsin $\theta$

$\mathrm{I}_{\text {rmsT } 4}^{2}=\frac{1}{2 \pi} \int_{0}^{\pi} \mathrm{I}_{\mathrm{uu}}^{2} \mathrm{D}_{\mathrm{T} 4}^{\prime} \mathrm{d} \omega \mathrm{t}=\frac{1}{2 \pi}\left[\frac{\mathrm{I}_{\mathrm{u}}^{2}}{4}\left(\frac{\pi}{2}+\mathrm{M}\left[1+\frac{\cos 2 \varphi}{3}\right]\right)+\right.$ $\left.\mathrm{I}_{\mathrm{ud}}^{2}(\pi+2 \mathrm{M})+\mathrm{I}_{\mathrm{uz}}^{2}\left(\frac{\pi}{2}+\mathrm{M}\left[1+\frac{\cos 2 \theta}{15}\right]\right)\right]$
$\mathrm{I}_{\text {rmsT 2 }}^{2}=\mathrm{I}_{\text {rmsT } 4}^{2}$

And for the T2 and T3 on-state period,

$\mathrm{I}_{\mathrm{T} 2}=\frac{1}{2 \pi} \int_{0}^{\pi} \mathrm{I}_{\mathrm{uu}} \mathrm{D}_{\mathrm{T} 2}^{\prime} \mathrm{d} \omega \mathrm{t}=\frac{1}{2 \pi}\left[-\frac{\pi}{4} \mathrm{MI}_{\mathrm{u}} \cos \varphi-2 \mathrm{MI}_{\mathrm{ud}}+\right.$ 23MIuzsin $\theta$

$\mathrm{I}_{\mathrm{T} 3}=\mathrm{I}_{\mathrm{T} 2}=\frac{1}{2 \pi}\left[-\frac{\pi}{4} \mathrm{MI}_{\mathrm{u}} \cos \varphi-2 \mathrm{MI}_{\mathrm{ud}}+\frac{2}{3} \mathrm{MI}_{\mathrm{uz}} \sin \theta\right]$

$\mathrm{I}_{\text {rmsT } 2}^{2}=\frac{1}{2 \pi} \int_{0}^{\pi} \mathrm{I}_{\mathrm{uu}}^{2} \mathrm{D}_{\mathrm{T} 2}^{\prime} \mathrm{d} \omega \mathrm{t}=-\frac{1}{2 \pi}\left[\frac{\mathrm{I}_{\mathrm{u}}^{2}}{4} \mathrm{M}\left[1+\frac{\cos 2 \varphi}{3}\right]+\right.$

2Iud2M+Iuz2 M1+ $\cos 2 \theta 15$

$\mathrm{I}_{\text {rmsT 2 }}^{2}=\mathrm{I}_{\text {rms } 3}^{2}$

The average value and RMS values of the current for the Diodes D1 to D4 for each switching period are calculated. For the period of D1 and D4 conduction, the average values of currents are,

$I_{D 1}=I_{D 4}=-I_{T 1}=-\frac{1}{2 \pi}\left[\frac{\pi}{4} M I_{u} \cos \varphi+2 M I_{u d}-\right.$

23MIuzsin $\theta$

$I_{r m s D 1}^{2}=I_{r m s D 4}^{2}=I_{r m s T 1}^{2}$

For the period when D1 and D3 are conducting,

$I_{D 1}=-I_{T 1}=-\frac{1}{2 \pi}\left[\frac{I_{u}}{2} \cos \varphi\left(1-\frac{\pi M}{4}\right)+I_{u d}(\pi-2 M)+\right.$

23MIuzsin $\theta$

And

$I_{D 3}=I_{T 1}=\frac{1}{2 \pi}\left[\frac{I_{u}}{2} \cos \varphi\left(1-\frac{\pi M}{4}\right)+I_{u d}(\pi-2 M)+\right.$ 23MIUzsin $\theta$

$I_{r m s D 3}^{2}=I_{r m s D 1}^{2}==I_{r m s T 1}^{2}$

Similarly, for the period of D2 and D4 conduction,

$I_{D 4}=-I_{T 4}=-\frac{1}{2 \pi}\left[\frac{I_{u}}{2} \cos \varphi\left(1+\frac{\pi M}{4}\right)+I_{u d}(\pi+2 M)-\right.$

23MIuzsin $\theta$

$I_{D 2}=I_{T 4}=\frac{1}{2 \pi}\left[\frac{I_{u}}{2} \cos \varphi\left(1+\frac{\pi M}{4}\right)+I_{u d}(\pi+2 M)-\right.$

23MIuzsin $\theta$

$I_{r m s D 4}^{2}=I_{r m s D 2}^{2}=I_{r m s T 4}^{2}$

And for the period when D2 and D3 are conducting,

$I_{D 2}=I_{D 3}=-I_{T 2}=-\frac{1}{2 \pi}\left[-\frac{\pi}{4} M I_{u} \cos \varphi-2 M I_{u d}+\right.$

23MIuzsin $\theta$

$I_{r m s D 3}^{2}=I_{r m s D 2}^{2}=I_{r m s T 2}^{2}$

Switching losses for the transistors $\mathrm{T} 1$ to $\mathrm{T} 4$ are calculated using equation (8). Therefore,

$P_{s w T 1}=\frac{f_{s} k}{2 \pi} \int_{0}^{t} k I_{u u}(\omega t) d \omega t=\frac{f_{s} k}{2 \pi}\left[I_{m} \cos \varphi+\pi I_{u d}\right]=$

$P_{\text {SWT } 2}=P_{\text {SWT } 3}=P_{\text {SwT }}$

The diodes switching losses are not considered, as they are turned on and off very fast, hence, the losses are very small compared to IGBTs. 


\section{EFFICEINCY EVALUATION OF FULL BRIDGE SUB MODULE: CASE STUDY}

Efficiency and losses evaluation of full bridge sub module is carried out by developing a program using MATLAB. The loss characteristic of full bridge sub module is studied for different values of modulation index, switching frequency and power angle. Table 2 shows the parameters used for the analysis.

Considering the conduction period when the voltage across the sub module is $+V_{c a p}$, the losses and efficiency graphs are here discussed only. During other conduction periods the characteristics' graphs follow the same pattern. Figure3 and Figure4 show the average currents and conduction losses of diode D1and D4 for the stated period respectively. The conduction losses increase with the increase of power angle and modulation index. The conduction losses reaches to maximum point at power angle $180^{\circ}$.

Table 2. Parameters Used for Analysis

\begin{tabular}{|l|l|}
\hline Parameter & Value \\
\hline Rated MMC Capacity & $200 \mathrm{MVA}$ \\
\hline Switching Frequency of each IGBT & $300 \mathrm{~Hz}$ \\
\hline Rated Frequency & $60 \mathrm{~Hz}$ \\
\hline IGBT Forward Resistance & $3.5 \mathrm{~m} \Omega$ \\
\hline IGBT Threshold Voltage & $3.5 \mathrm{~V}$ \\
\hline Freewheeling Diode Forward Resistance & $3.0 \mathrm{~m} \Omega$ \\
\hline Freewheeling Diode Forward Voltage & $2.5 \mathrm{~V}$ \\
\hline
\end{tabular}

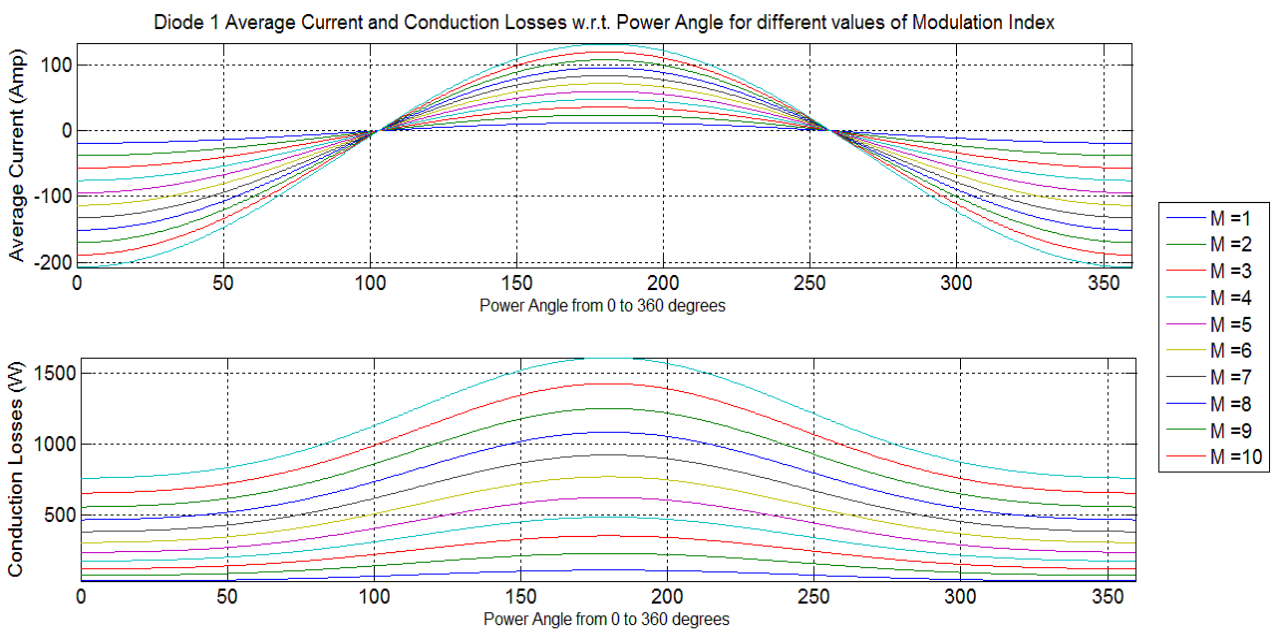

Figure 3: Diode D1 Average Current and Conduction Losses
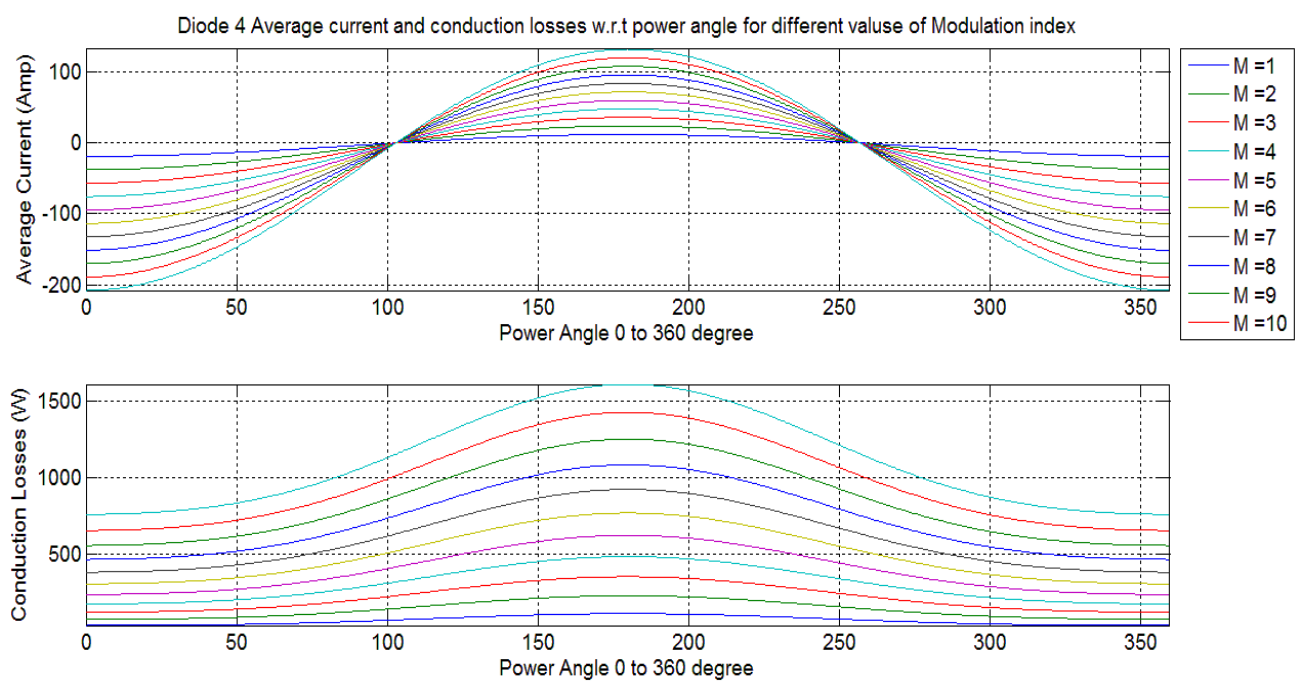

Figure 4: Diode D4 Average Current and Conduction Losses

Figure 5 and Figure 6 show the average currents, conduction losses and switching losses of IGBTs T1 and T4 respectively. In this case, the conduction losses decrease with the increase of power angle and reaches to minimum at angle of $180^{\circ}$.
While the switching losses increase with the increase in switching frequency and is at minimum value at an angle of $180^{\circ}$ 


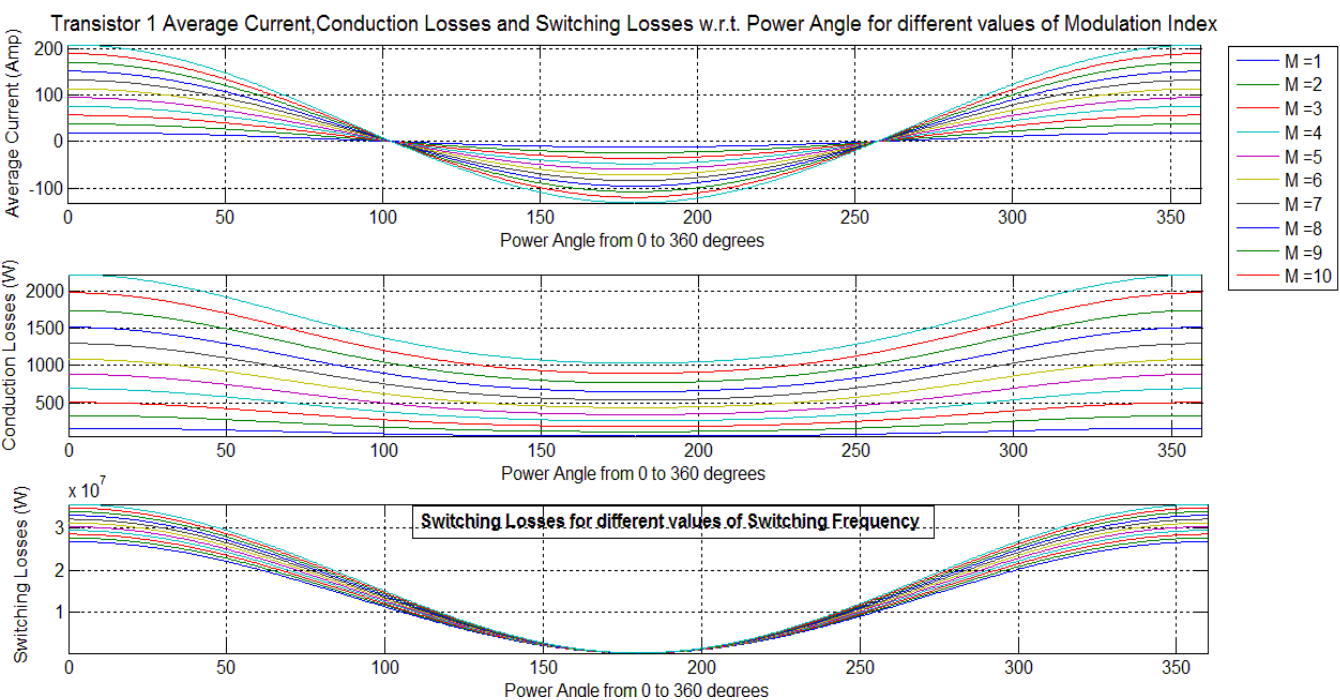

Figure 5: Transistor T1 Average Current, Conduction Losses and Switching Losses
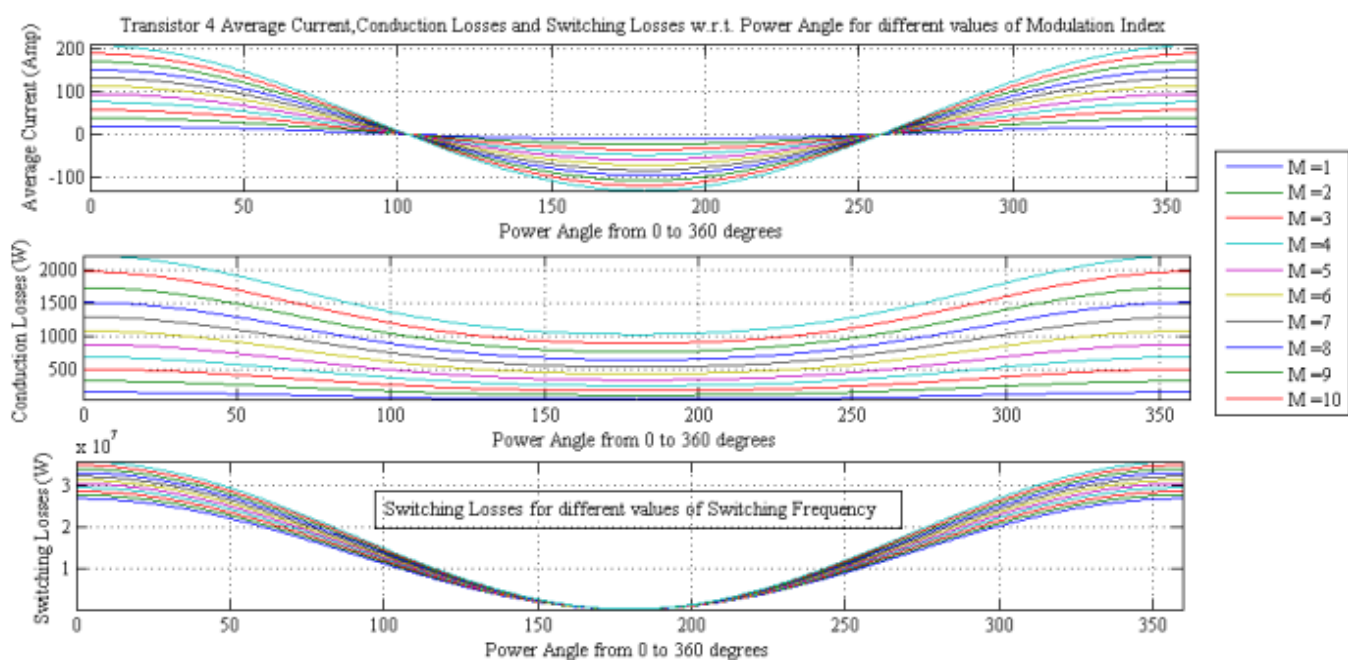

Figure 6: Transistor T4 Average Current, Conduction Losses and Switching Losses

The total power losses characteristic graph of full bridge sub module is shown in Figure 7. The losses increase with the increase in the power angle and modulation index. The losses are at the peak value at the power angle of $180^{\circ}$. The losses are dependent on power angle, modulation index and switching frequency. The increase in switching frequency also results in the increase of total power losses.

The efficiency of full bridge sub module for the particular case is described with the help of Figure 8 the efficiency of the sub module increases with the increase in the power angle, it has a maximum values at $180^{\circ}$. The increase in modulation index decreases the efficiency. While the switching frequency has the same effect on the efficiency as the modulation index has on it.

\section{CONCLUSIONS}

In this paper the loss characteristics of full bridge sub module were discussed in detail. The structure of MMC based HVDC system was discussed; also the types of losses in the converter were also discussed. An analytical method based on average and RMS values of current was presented. The losses equations were derived using the presented method. Finally, MATLAB based program was developed to analyze the losses and efficiency of the sub module. 


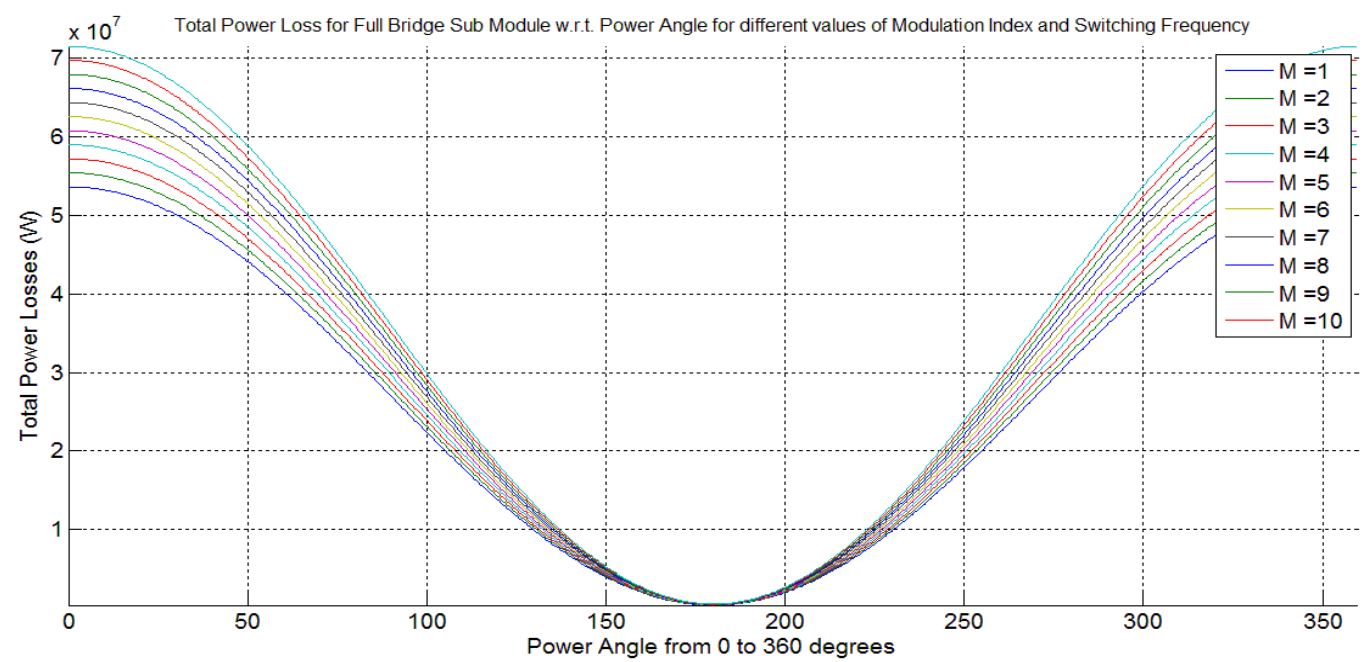

Figure 7: Total Power Losses of Full Bridge Sub Module

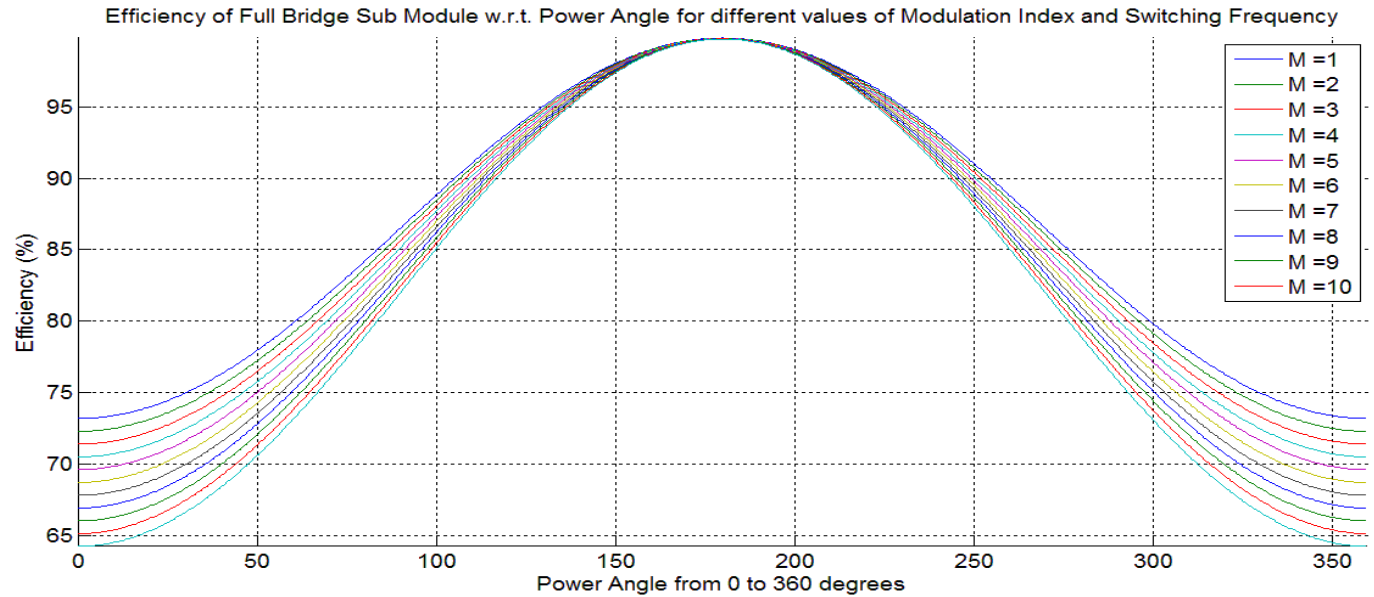

Figure 8: Efficiency of Full Bridge Sub Module

The conclusions derived on the basis of the method presented are study as following:

1. The diodes conduction losses increase with the increase in the power angle but increase with the increase in the modulation index.

2. Increasing the power angle decreases the conduction losses and switching losses of the transistors; IGBTs. While the increase in the values of the modulation index results in increases of the conduction losses.

3. The switching frequency has a direct impact on the switching losses.

4. The transistors; IGBTs total losses are always greater than their respective diodes.

5. The total losses are dependent on the power angle, modulation index and switching frequency. Only the power angle has indirect impact on the total losses while the other two have direct impact.

6. The efficiency of the sub module is maximum at the power angle of $180^{\circ}$. While increase in the values of modulation index and switching frequency decreases the efficiency.

\section{REFERENCES}

[1] Hui P, "Evaluation of losses in VSC-HVDC transmission system," Power and energy society general meeting conversion and delivery of electrical energy in the 21 st century, 2008 IEEE; 2008. p. 1-6..

[2] Blaabjerg F, "Power losses in PWM-VSI inverter using NPT or PT IGBT devices," IEEE Trans Power Electron, vol.10, p.358-67, 1995.

[3] Oh KS. Application note 9016: IGBT basics 1, FAIRCHILD Semiconductor, Rev. A2; February 2001.Tavel, P. 2007 Modeling and Simulation Design. AK Peters Ltd.

[4] Wei L, L.-A. Grégoire, J. Bélange, "Modeling and Control of a Full-Bridge Modular Multilevel STATCOM," IEEE Power and Energy Society General Meeting, 2012 IEEE; p. 1-7, July 2012. 